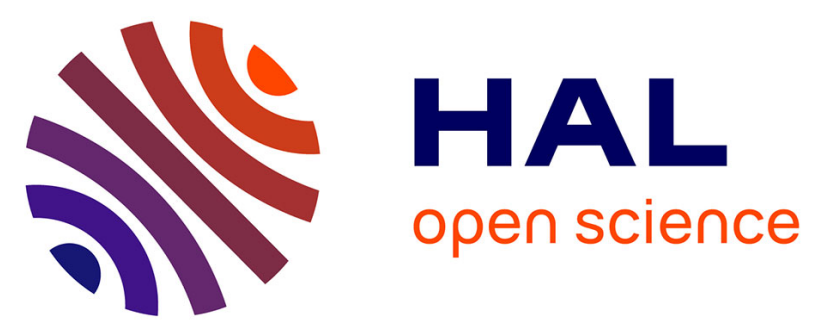

\title{
New molecular simulation method to determine both aluminum and cation location in cationic zeolites
}

\author{
Marie Jeffroy, Carlos Nieto Draghi, Anne Boutin
}

\section{To cite this version:}

Marie Jeffroy, Carlos Nieto Draghi, Anne Boutin. New molecular simulation method to determine both aluminum and cation location in cationic zeolites. Chemistry of Materials, 2017, 29 (2), pp.513-523. 10.1021/acs.chemmater.6b03011 . hal-01420911

\section{HAL Id: hal-01420911 \\ https://hal.sorbonne-universite.fr/hal-01420911}

Submitted on 21 Dec 2016

HAL is a multi-disciplinary open access archive for the deposit and dissemination of scientific research documents, whether they are published or not. The documents may come from teaching and research institutions in France or abroad, or from public or private research centers.
L'archive ouverte pluridisciplinaire HAL, est destinée au dépôt et à la diffusion de documents scientifiques de niveau recherche, publiés ou non, émanant des établissements d'enseignement et de recherche français ou étrangers, des laboratoires publics ou privés. 


\section{INTRODUCTION}

Zeolites are nanoporous crystalline materials that find wide applications in industrial processes, as catalyst, adsorbent or ion exchanger. Over the past 100 years a huge number of zeolites have been synthesized with various pore size and geometry. ${ }^{1}$ The adsorption and diffusion properties of molecules inside the zeolitic porous volume play a crucial role in the various processes using zeolites. ${ }^{2}$

Zeolitic materials are aluminosilicate porous solids. Starting from a purely siliceous material, the substitution of a tetravalent silicon atom by a trivalent aluminum atom on a T-site introduces a charge defect that is compensated by a non-framework cation. Adsorption properties of aluminosilicate zeolites are closely related to the location of nonframework cations ${ }^{3}$. Location of aluminum atoms can strongly influence the cation location. ${ }^{4,5,6}$ It is therefore important to get some insights on the aluminum repartition inside the unit cell of zeolite.

Due to their large range of applications, many experimental studies have been devoted to zeolites. Structure determinations by $\mathrm{RX}$ or neutron experiments have been done for several materials allowing the creation of a database of zeolites structures. ${ }^{1}$ Although the determination of the mean structure and the chemical composition of a zeolite are well established, experimental aluminum distribution measure remains a challenge. Aluminum and silicon atoms are almost impossible to discriminate by the conventional RX methods. Recent experimental developments have however allowed to determinate the aluminum repartition in few cases (see below).

Since it is very hard to get a direct determination of aluminum siting, this repartition remains a subject of much debate with large number of dedicated research studies. The so-called Lowenstein rule, which states that two aluminum atoms cannot be neighbors of a common oxygen atom, is the only commonly admitted rule in this subject, 7 even if some exceptions have been observed. ${ }^{8}$ For materials having a Si:Al ratio very close to one, the Lowenstein rule imposes an alternated repartition of the silicon and aluminum atoms in the Tsites of the material. For the other Si:Al ratio, very few is known about the aluminum repartition on the zeolitic framework. Even if direct determination is limited to very few cases, other technics such as ${ }^{29} \mathrm{Si}$ or ${ }^{27} \mathrm{Al} \mathrm{NMR}$ technics as well as the analysis of the TO distances from the average structure measured by RX give some indications that in many cases the distribution may be nonrandom. $9,10,11,12$

Silicon or aluminum NMR techniques have been ap-

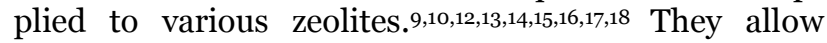
identifying different environments for aluminum atoms. In materials with a small number of different Tsites, the attribution of the different picks can be done but the determination of the aluminum repartition of the sites remains subject to interpretation.9,13 Recently, the aluminum repartition has been determined for high silica materials.10,16,19 Sklenak et al. observed that the 
aluminum repartition depends on the synthesis mode of the material. ${ }^{16}$

Extended X-ray adsorption fine structure (EXAFS) experiments can bring some information about the direct environment of aluminum atoms such as distances, number and nature of neighbors atoms, though this information cannot be directly interpreted to deduce the aluminum repartition. ${ }^{20,21,22}$ Using X-ray standing waves, van Bokhoven et al. succeeded in determining unambiguously the aluminum repartition in Scolecite. ${ }^{23}$ Very recently, a quantitative analysis was reported that uses a combination of EXAFS and ${ }^{27} \mathrm{Al}$ MAS NMR spectroscopy ${ }^{24}$.

Average T-O distance and TOT angle for each T-site of the average structure can give some indirect indication of the aluminum location on the zeolite framework. Some information about aluminum occupancy of the different T-sites are usually extracted from analysis of the mean T-O distance of a particular T-site, longer T-O distance been indicative of a higher $\mathrm{Al}$ occupancy. ${ }^{25,26}$ Those results have to be taken with particular caution since extraframework cations location also has an influence on this mean average distance. ${ }^{27}$ The cation location can also be incorporated in models, to take this effect into account. ${ }^{11}$

Simulation studies have been used to help in the determination of aluminum repartition in the framework. Several studies have been done to determine the energy of replacing an aluminum atom by a silicon one, using quantum mechanics (QM) or empirical potentials. ${ }^{28,29}$, ,30 However, these calculations do not allow to predict the aluminum repartition for low silica materials, since long-range electrostatic repulsion play an important role in those cases. ${ }^{31,32}$

Lewis and co-worker have employed energy minimization using an empirical forcefield to study the aluminum repartition of different natural materials. Ruiz Salvador et al. showed that the most stable aluminum repartition inside the framework for a small $\mathrm{Si}$ :Al ratio cannot be predicted by calculating the substitution energy of one silicon by aluminum atom. ${ }^{31}$ They studied the different possible configurations of aluminum (the number has been reduced by taking into account the Lowenstein rule as well as symmetry constraints) to find the most stable one. This methodology was successfully applied to Heulandite, and Clinoptilolite zeolites. ${ }^{31,33,34}$ However, in the case of Goosecreekite the method fails to predict the experimental aluminum repartition. 35 French et al. have demonstrated that Monte Carlo and energy minimization methods can successfully be used to explore aluminum repartition in zeolites using a large distributed computing approach. ${ }^{36}$

A different approach was introduced by Soukoulis using Monte Carlo simulations to generate a large number of Si:Al configurations in a diamond rigid lattice. 37 The model only contained interactions between first and second neighbors, and the parameters where adjusted to reproduce the experimental Si NMR spectra of Faujasite. Similar methods were applied by Herrero et al. to Faujasite, LTA, and Chabasite using the experi- mental crystallographic structures. In a first approach, Herrero et al. include only short-range interactions. ${ }^{38}$ Later version of the model includes long-range interactions ${ }^{39}$ between the aluminum and silicon atoms, as well as the polarization energy of the oxygen atoms. ${ }^{1440}$ The methodology is restricted to zeolites with a single T-site. Soukoulis model was extended to materials having different T-sites by adjusting different parameters for the different sites, ${ }^{41}$ or by adding in the calculation the relative energy of the different T-sites. ${ }^{42}$ In this family of methods, extraframework species are never taken into account.

Adsorption and diffusion properties of the zeolitic materials have been extensively studied by molecular simulation. ${ }^{43,44,45,46,47}$ Forcefields to describe interactions between adsorbate and adsorbent, but also to model the flexibility of the framework have been developed with success. $48,49,50,51,52,53,54,55,56,57,58,59$ To overcome the general problem of the lack of information about aluminum location, two general approaches have been developed. The first one models explicitly the aluminum and silicon atoms in the framework and considers one or several random aluminum distribution (taking into account the Lowenstein rule).51,52,53,56,60 The results are then usually averaged over different repartitions of aluminum atoms. However, in these methods, the number of considered repartitions remains low to be statistically fully representative. The second approach, usually called T-atom model, considers that aluminum and silicon can be modeled as an average atom, whose physical properties are intermediate between the aluminum and the silicon ones. ${ }^{50,54,61}$ Both approaches can lead to satisfactory results.

Different studies analyzed the influence of the explicit representation of aluminum atoms on extraframework cation location and adsorption properties. MellotDraznieks et al. compared the results given by two different models, one with explicit Si:Al and the other using average T-atoms on the extraframework cation distribution of the $\mathrm{NaX}$ zeolite. 4 Calero et al. studied the influence of the aluminum repartition on the adsorption properties of alkanes on eight zeolitic materials.5,6 They divided the materials in two groups: some in which the adsorption properties are sensitive to the chosen aluminum repartition, and the other which are not. By comparing the calculated adsorption properties with the experiments for the first group of materials, they can indirectly deduce the aluminum repartition on the framework of these materials. However, since the adsorption properties have to be calculated for each possible aluminum repartition of the material, this method is restricted to simple cases, where only a small number of distributions are possible.

Therefore, a need exists to design a new methodology to take into account a large number of aluminum atoms configurations, corresponding to the experimental repartition over the different unit cells.

In the present paper, we propose a new methodology to predict aluminum atoms repartition in a given zeolitic structure, as well as the extraframework cation location in various thermodynamic conditions, such as hydra- 
tion. This methodology allows generating a huge number of aluminum atoms configurations along the simulation. To our knowledge this is the first time that the properties of the materials are averaged over all the different configurations in the thermodynamic limit (and not only over the few lowest-energy configurations). This method differs from and complements energy minimization approaches on three main points: 1. it does not include any local relaxation of the framework, thus does not look for the most stable structure of the complete material. 2. It focus on the determination of aluminum atoms and cations distribution in a given average zeolite framework. It thus allows predicting a distribution for different experimental structures that can be obtained for the same materials but various synthesis ways. 3. It is fully compatible with standard MC adsorption simulation and allows computing thermodynamic properties averaged over equilibrium distribution. The method has been applied to tens of zeolitic materials.

The paper is organized as follow. The proposed methodology will be detailed in the next section. Later, the aluminum repartition obtained for various zeolites will be presented, and compared with experimental data. Finally, the question of the extraframework cation distribution will be addressed in the presence of adsorbed molecules (water) followed by the conclusion and perspectives.

\section{METHODOLOGY}

2.1 Simulation method: This method aims at determining the aluminum repartition over the different T-sites of zeolites. The proposed method introduces in standard Monte Carlo simulations a new move to exchange aluminum and silicon atoms on the different $\mathrm{T}$ sites of the material. The new configuration is accepted on the basis of an energy criterion, like for standard Monte Carlo simulations. In this way, the calculated properties of the material on the simulation are averaged on many aluminum and silicon atoms configurations in the thermodynamic limit (statistics are usually performed on $\sim 1.10^{5}$ configurations).

It is worth noticing that the generation of the configuration takes into account not only the interactions between framework atoms $\left(N_{\mathrm{Al}}, N_{\mathrm{Si}}\right)$, but also interactions with extraframework cations ( $\left.N_{\text {cations }}\right)$ and potential adsorbed species $\left(N_{\text {ads }}\right)$. Simulations are done at constant $\left(N_{\mathrm{Al}}, N_{\mathrm{Si}}, N_{\text {cations }}, \mathrm{V}, \mathrm{T}\right)$, where the extra-framework cations can explore together the whole space of configurations whereas the silicon and aluminum atom coordinates are restricted within the T-sites of the structure. One can then write the partition function of the system as follows:

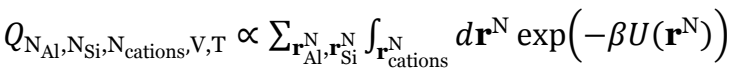

The new MC move concerns the exchange of randomly selected $\mathrm{Si}$ and $\mathrm{Al}$ atoms and is accepted with the following probability,

$P_{a c c}=\frac{e^{-\beta \Delta U_{i j}}}{Q_{\mathrm{N}_{\mathrm{Al}}, \mathrm{N}_{\mathrm{Si}}, \mathrm{N}_{\text {cations }}, \mathrm{V}, \mathrm{T}}}$
The energy $\left(\Delta \mathrm{U}_{\mathrm{ij}}\right)$ term is calculated using an analytical forcefield (see section 2.4). This MC move can be easily implemented in Grand Canonical ensemble when simulating adsorption phenomena (fix $\mu_{\text {ads }}$ ).

Moreover, the framework structures are considered fixed along the simulation, the aluminum and cation locations thus correspond to the expected thermodynamic equilibrium for a given set of $\mathrm{T}$ and $\mathrm{O}$ coordinates. Additional technical details and a critical analysis of the method are available in the SI.

2.2 Zeolite model: the zeolitic structure is taken from RX experimental structure determination. The zeolitic structure is considered rigid to limit the cost of the simulation. In principle, the method could be applied for flexible structures (using a realistic force field for the framework) with however a significant increase of the computation time. Since the $\mathrm{Si}$ :Al ratio simulated corresponds to the experimental one; the footprint of the experimental aluminum repartition is contained in the average structure. Thus without taking into account explicitly the flexibility, our model can still be sensible to differences on the T-atoms environment.

2.3 Zeolite structures and composition: The structures of zeolites were taken from experimental diffraction studies characterizations: Analcime (ANA), ${ }^{62}$ Faujasite (FAU), ${ }^{63}$ Ferrierite (FER), ${ }^{64}$ Goosecreekite (GOO), ${ }^{65}$ Linde Type A (LTA), ${ }^{66}$ Linde Type L (LTL), ${ }^{67}$ Mordenite (MOR), ${ }^{68}$ Natrolite (NAT), ${ }^{69}$ Theta-1 (TON) ${ }^{70}$ Mobil FIve (MFI), ${ }^{71}$ and Mobil ELeven (MEL). ${ }^{72} \mathrm{Si}$ :Al ratio of the simulated material was chosen as close as possible to the experimental one. Cations and water molecules are explicitly represented in the simulation box. In this work all extraframework cations in the simulation are sodium. For experimental hydrated structures, the experimental number of water molecules has been incorporated in the simulation box. The exact composition of the simulated zeolites can be found in supplementary information (SI).

2.4 Forcefield: Within the framework, the silicon, aluminum and oxygen atoms interact via electrostatic interactions. Parameters describing the interaction between adsorbent and extraframework cation were taken from previous studies.50 The total energy of the system was computed using an electrostatic and a repulsive dispersion terms. We used the Kiselev approximation for the dispersion-repulsion term between adsorbate or extraframework cations and adsorbent.73 Interaction energy between sodium and oxygen was modeled with a Buckingham potential adjusted by Jaramillo et al.49 The Lennard-Jones potential parameters for oxygen atoms (O-O) were adjusted in a previous work. 74 These parameters were successfully used to reproduce alkanes, alkenes and water adsorption in various types of zeolites.50,75,76,77,78,79 Water molecules were modeled with the well-known model TIP4P.80 This model has already successfully been used to simulate the adsorption properties of various siliceous and cationic zeolites. ${ }^{0,78}$ The sodium cation-water LJ interactions parameters are taken from the work of Dang et al. ${ }^{81}$ All cross parameters have been obtained using the 
Lorentz-Berthelot mixing rules. All interaction parameters are provided in SI.

2.5 Simulation details: All simulations were done using the canonical ensemble $(\mathrm{N}, \mathrm{V}, \mathrm{T})$. The method is easily extendable to the Grand Canonical ensemble to calculate adsorption isotherms. The usual translation and rotation moves were used for the extraframework species. In order to accelerate convergence a bias "translational jump move" was used. This move consists in a deletion followed by an insertion for a particular molecule in order to do a long distance translation inside the simulation box. More detail about this move can be found in ref. 50. The runs lasted for some 200 million steps.

\section{RESULTS AND DISCUSSION}

3.1 Aluminum atoms location: convergence test: The average aluminum atoms repartition has been calculated for several zeolitic topologies (containing between 1 and 12 different crystallographic T-sites): MOR, TON, MFI, NAT, FER, LTL, ANA, FAU, LTA, GOO, MEL. Among these structures, in the LTA and FAU framework all the T-sites are crystallographic equivalent. NAT and GOO are usually classified in the group of ordered materials, meaning that the aluminum atoms repartition is considered non-random.

The average occupancy of the T-sites has been calculated from the configurations obtained during the simulations using the average experimental structure of the framework as an input information. The example of Goosecreekite is presented in Figure 1. We observed that crystallographically equivalent T-sites have the same aluminum occupancy within statistical uncertainties. This indicated that the convergence is reached in our simulations.

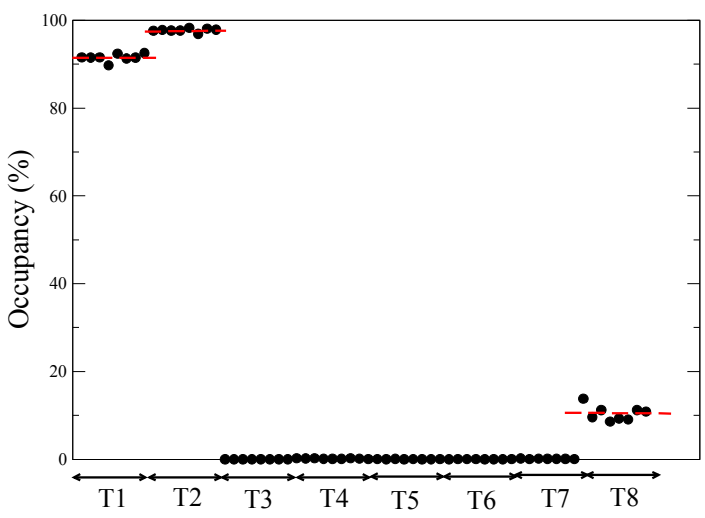

Figure 1. Aluminum repartition in Goosecreekite material. The percentage of occupancy for the different T-site is represented. Site $\mathrm{T} 1$ and $\mathrm{T} 2$ are almost fully occupied. The only other significantly occupied site is site T8.

3.2 Comparison with experimental data: Scolecite material: The study by Van Bokhoven et al. de- termined the aluminum location on a particular material: the Scolecite zeolite. ${ }^{23}$

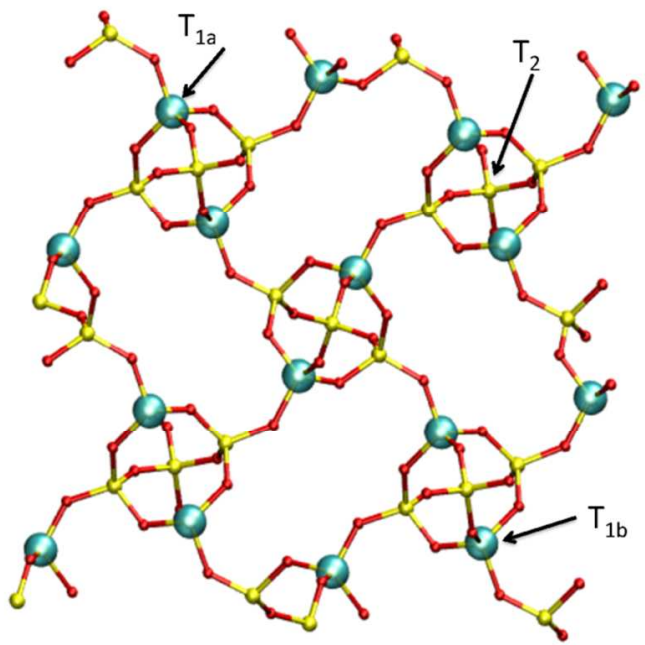

Figure 2. Scolecite structure. Blue spheres represent the aluminum repartition over the different T-sites of Scolecite. The sphere diameter is proportional to the site occupancy.

Scolecite is a natural zeolite belonging to the NAT group. Its structure is represented on figure 2. This material has 5 different $\mathrm{T}$ sites labeled from T1a, T1b, T1c, T1d and T2 as in ref 23. The material used by Van Bokhoven et al. is hydrated. It has a $\mathrm{Si}: \mathrm{Al}$ ratio of 1.5 . For our simulations, we used a structure from Fälth and coll..$^{82}$ of a natural Scolecite. We used a Si:Al ratio of 1.55 which is slightly higher than in ref. 23. The reason is that with a $\mathrm{Si}$ :Al ratio of 1.5 we rapidly reach a blocked configuration since all $\mathrm{Si}-\mathrm{Al}$ exchanges performed lead to neighboring aluminum atoms, which is forbidden due to the Lowenstein rule. To avoid this problem, we could replace the total interdiction of having two neighboring aluminum atoms by an energetic penalty for a pair of aluminum neighbors. However, the value of this penalty would have to be adjusted, probably to a different value for the different zeolites, and we choose not to introduce an additional parameter.

Our simulation results show that aluminum atoms are located in sites T1a and T1b. The occupancy of the different $\mathrm{T}$ sites is represented in Figure 2. These results are in perfect agreement with the experimental results of Van Bokhoven et al.23 These results indicate the capacity of our model to capture the physics of the studied systems.

The same method has been applied to different materials in order to find some insight on the parameters governing the aluminum distribution on these systems.

3.3 Comparison with other methods based on average distances and angles: Different methods exist for the determination of the aluminum repartition of the different T-sites using the average experimental structure as an input information. The first one extracts the aluminum occupancy of the different T-sites direct- 
ly from average T-O distance of each T-site. Jones ${ }^{25}$ and later Ribbe et al. ${ }^{26}$ established two different linear relations between the T-O distance and the aluminum atom occupancy. Those relations works well for completely disordered aluminum atoms repartitions, but always underestimate the total number of aluminum atoms of the partially ordered materials. Alberti et al. proposed a corrected version of this method including angular constraints and the presence of extra framework cations. This method leads to better agreement between the estimated $\mathrm{Si}$ Al ratio and the experimental one, though some discrepancy still exists. ${ }^{11,27,83}$

To compare our simulation results to the estimations obtained by those methods, we studied a material belonging to the MOR family completely exchanged with sodium whose structure has been published by Schlenker et al. ${ }^{84}$ The simulated Si:Al ratio was of 5 , leading to 8 sodium cations/uc.

Our simulation results are represented in Figure 3 whereas the percentage of aluminum occupancy obtained in our simulations are compared with experiments and the results obtained by Jones and Alberti methods in Figure $4 \cdot{ }^{17,18}$

The order of occupancy of the sites obtained by all the methods is the same: $\mathrm{T}_{3}>\mathrm{T}_{4}>\mathrm{T} 1>\mathrm{T} 2$.

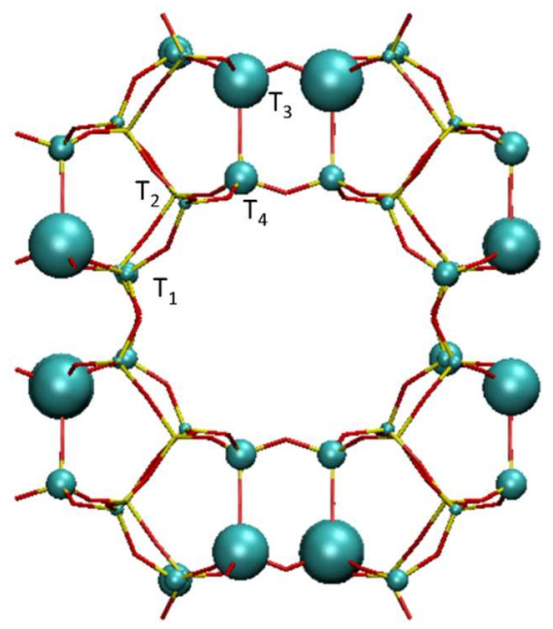

Figure 3. Aluminum repartition calculated by simulation of the different $\mathrm{T}$ sites $\left(\mathrm{T}_{1}, \mathrm{~T}_{2}, \mathrm{~T}_{3}\right.$ and $\left.\mathrm{T}_{4}\right)$ of Mordenite. The sphere diameter is proportional to the aluminum population in the corresponding site.

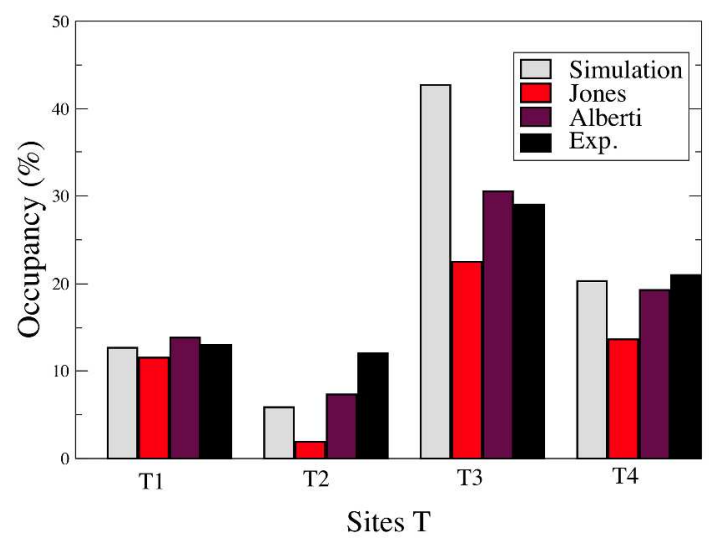

Figure 4. Comparison of aluminum occupancy of the different T-sites of Mordenite calculated with different methods: our results (grey), using Jones'25 model (red), using Alberti's ${ }^{11}$ model (purple) and experiments from refs 17 and 18 .

These results are also in perfect agreement with other experimental studies. 85 By analyzing experimental cations location, Schlenker et al. as well as Meier et al. suggest that the aluminum atoms are probably located in sites $\mathrm{T}_{3}$ and $\mathrm{T}_{4}{ }^{84,86}$ Kato et al. studied the aluminum location on two groups of different mordenite by ${ }^{29} \mathrm{Si}$ MAS NMR, one group is synthesized in the presence of fluoride ion and the other following the conventional way. ${ }^{15}$ Their results suggest that aluminums are located in $\mathrm{T} 1, \mathrm{~T} 2$ and $\mathrm{T}_{4}$ in the fluored samples whereas they occupy all the different T-sites in conventional structures. This suggests that the aluminum atoms location depends on the synthesis mode. This question will be further discussed in the following section. Calero et al. studied by molecular simulation the adsorption of alkanes in sodium Mordenite. ${ }^{11}$ They calculated the adsorption isotherm and Henry constants for the different possible aluminum repartitions in this material. By comparison with the experimental adsorption properties, they concluded that the aluminum atoms are located in the $\mathrm{T}_{3}$ and $\mathrm{T}_{4}$ sites of the Mordenite framework. Moreover French et al. by minimizing a large amount of randomly distributed aluminum have obtained a larger occupancy of $\mathrm{T}_{3}$ over $\mathrm{T} 4$ for lowest energy structures. ${ }^{6}$ Our simulation results fairly agree with all these findings.

The comparison between our simulation results and the prediction by the Alberti's method agrees well. This is not only the case for Mordenite materials, but also for several other materials we studied by simulation belonging to the GOO and ANA families. All the results are reported in SI. It is important to note that our simulation model is sensible to the geometric parameters distances of the framework, but also to the angles and cation location. 
3.4 The case of Analcimes: influence of the synthesis way: It has been suggested that the aluminum location may depend on the synthetic way. Sklenak et al. reported different aluminum repartition on MFI zeolites $^{16}$ and Kato et al. for different MOR zeolites. ${ }^{15}$

Mazzi and Galli published a series of natural Analcime structures, whose samples come from different origins. ${ }^{87}$ The samples almost have the same composition and $\mathrm{Si}: \mathrm{Al}$ ratio. We calculated the aluminum distribution of the different samples. We chose to use a Si:Al ratio of 2.2, instead of 2 to avoid having blocked configurations due to the Lowenstein rule. The detailed composition of the simulated samples is reported in SI. In this case we simulated a fully hydrated sample.

Simulation results are reported for two different samples ANA1 and ANA6 in Figure 5 (for the description of the samples see ref 87). Their structure contains two different $\mathrm{T}$-sites $\mathrm{T} 1$ and $\mathrm{T} 2$. The repartition obtained by Mazzi et al. ${ }^{87}$ and by Jones equation and the Alberti methods ${ }^{11}$ are also reported. The results show that in ANA1 the most occupied site is T1 whereas in ANA6 the most occupied site is T2. This inversion for two materials having the same composition, and belonging to the same zeolitic group shows that the aluminum location is strongly dependent of the synthesis conditions. It must be noticed that again our method is in agreement with the prediction of Alberti et al.

a)

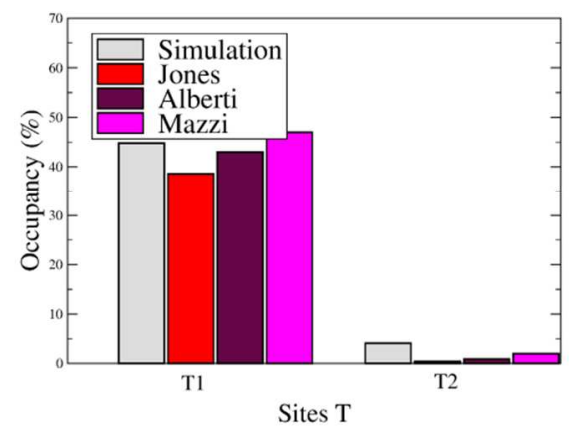

b)

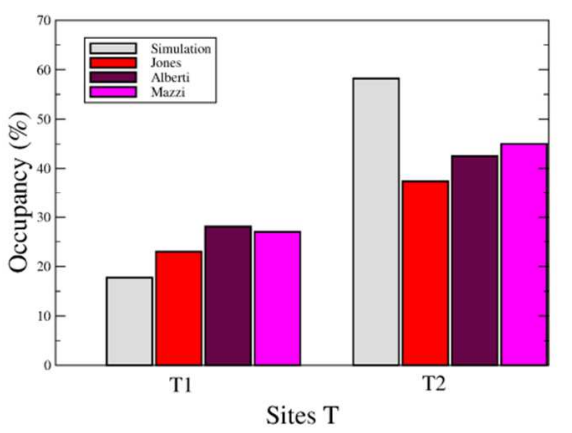

Figure 5. Aluminum repartition of (a) ANA1 and (b) ANA6.
It is worth noticing that the synthesized structures are metastable and the zeolite formation may not be thermodynamically driven. This limits the validity of the energy minimization approaches and may explain the discrepancy with experimental results obtained for some materials. 35 While not fully predictive, our method allows taking into account the variability in the framework structures depending on the synthetic routes. The proposed method is thus a useful alternative for aluminum location determination in complement to diffraction experiments.

3.5 Correlation with energy of sites: Aluminum distribution is very often predicted by calculating the energy of one aluminum atom located in the different T-sites of the material. This approach considers the energy of aluminum atoms embedded in a particular configuration, thus the repartition of aluminum atoms predicted this way does not take into account the interactions between distant aluminum atoms. We calculated with our method the energy minimum of each configuration of a system containing one aluminum atom located in one of the different T-sites of Mordenite and one cation free to move. The results are reported in Table 1. The aluminum distribution can then be estimated using Boltzmann probabilities (see SI for technical details).

The predicted distribution is represented in Figure 6 and compared to the simulation results. $\mathrm{T}_{3}$ is the most favorable site using both approaches. However the occupancy of the site obtained from energy calculation is overestimated compared to the simulation results. Simulation results reveal a partial occupancy of T1 and T2 whereas energies calculation predicts almost zero population. This example illustrates the influence of aluminum-aluminum interaction on the aluminum distribution. Ruiz-Salvador et al. reached similar conclusions in the case of Clinoptilolite ${ }^{31}$ and ZSM-5. ${ }^{88}$

Table 1. Energy of the different T-sites of Mordenite. This energy corresponds to the minimum energy of the structure containing one aluminum atom (and one sodium cation) per unit cell. The structure is considered rigid and the minimum corresponds to the most favorable location for the extraframework cation. For clarity reasons, only the relative energies compared with the most stable T-site are reported. The reported results have been obtained with the experimental structure published by Schlenker et al. ${ }^{84}$

\begin{tabular}{cc}
\hline T-site & Relative energy (K) \\
\hline $\mathrm{T} 1$ & 3081 \\
$\mathrm{~T} 2$ & 3072 \\
$\mathrm{~T} 3$ & 0 \\
$\mathrm{~T} 4$ & 1678 \\
\hline
\end{tabular}




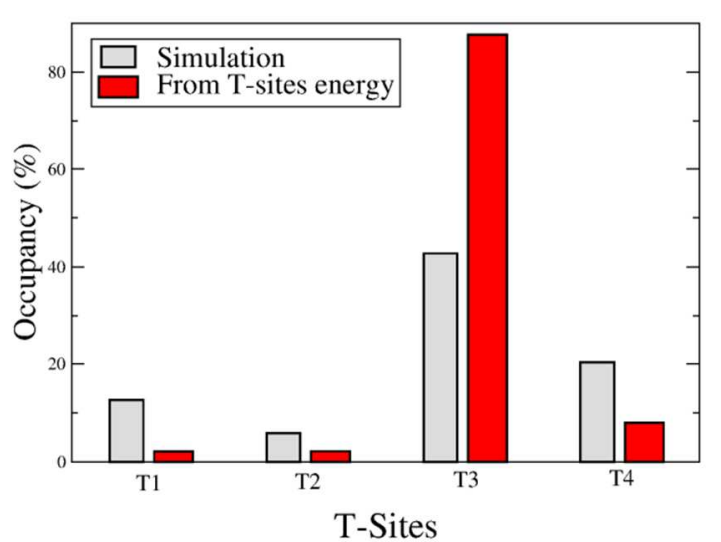

Figure 6. Aluminum repartition of MOR according to site energies (see text for definition).

3.6 Consequences of aluminum position on extraframework cation location: Since extraframework cations are free to move inside the simulation box, we can also obtain some information about their location. The cation distribution obtained corresponds to an average of the different cations distribution over different aluminum configurations.

The position of extraframework cation influences the material adsorption properties..$^{00,89}$ Thus, it is interesting to know the influence of the aluminum distribution on the extraframework cation location. This question is the object of the following sections.

3.6.1 Cation location-Comparison with experimental data: Extraframework cation location have been calculated for several zeolitic materials and compared to the experimental data when available. In this section, we will describe only the results for the materials for which we found some experimental data on cation location. All the additional results can be found in SI.

In Faujasite type zeolites, we observe in our simulations that extraframework cations location varies with the number of cations (Si:Al ratio). In $\mathrm{Na}_{48} \mathrm{Y}$, sodium cations occupy sites I, II. When the Si:Al ratio increases, the number of occupied site I decreases in favor of sites I' until all sites I' are occupied. Then sites III/III' start to be filled. These results are in agreement with experimental data (see Table 2).50

Schlenker et al. have studied the extraframework cation location in Na-exchange Mordenite by RX diffraction experiment. ${ }^{84}$ They published the zeolitic structure as well as the extraframework cation location inside the porous volume. A more recent work, by Maurin et al. studied the cation location in dehydrated Mordenite by combined ${ }^{29} \mathrm{Si}$ NMR and molecular simulation. ${ }^{60}$ These results are reported with our simulation results in Table 2. In Mordenite cations occupy sites I, IV and VI in agreement with experimental results.
Zeolite-L has been the subject of different experimental studies and the extraframework cation distribution has been characterized for various samples. We calculated the cationic distribution of sodium-exchanged LTL containing 9 sodium per unit cell. The structure is taken from a study of Baerlocher et al. on a hydrated sample..$^{90}$ The cation repartition has been calculated and is reported in Table 2 together with experimental data. We observe a good agreement when compared with the experiments. In all cases, sodium cations fully occupy sites B whereas sites C and D are partially occupied.

3.6.2 Influence of the aluminum location on the cationic distribution: Due to the atomic charge difference, the repulsion of sodium is expected to be smaller with an aluminum than with silicon atoms. Extraframework cations are thus expected to be located close to aluminum atoms.

In order to quantify the potential influence of an aluminum atom on the location of an extraframework cation we calculate the number of aluminum atoms close to an extraframework cation. We choose a threshold of $4 \AA$, which in most of the structures corresponds to the first minimum in the $\mathrm{Na}-\mathrm{Al}$ radial distribution function. However, this value is dependent on the $\mathrm{Si}: \mathrm{Al}$ ratio, i.e. the higher the $\mathrm{Si}: \mathrm{Al}$ ratio is, the smaller this value is expected to be. If the local $\mathrm{Si}: \mathrm{Al}$ ratio around a cation is lower than the global $\mathrm{Si}: \mathrm{Al}$ ratio, the cation is sensible to the presence of aluminum atom, and is located close to them. By analogy with selectivity coefficient in adsorption, we define an aluminum order parameter $\alpha_{\mathrm{NaAl}}$ for extraframework cation:

$$
\alpha_{N a A l}=\frac{n_{A l, l o c}}{n_{S i, l o c}} \frac{n_{S i, g l o b}}{n_{A l, g l o b}}=\frac{(S i: A l)_{g l o b}}{(S i: A l)_{l o c}}
$$

where $\mathrm{n}_{\mathrm{Al}, \mathrm{loc}}$ is the average number of aluminum atom close to an extraframework cation, $\mathrm{n}_{\mathrm{Si} \text {,loc }}$ is the average number of silicon atoms close to an extraframework cation, $\mathrm{n}_{\mathrm{Al}, \mathrm{glob}}$ the number of aluminum atoms per unit cell, and $\mathrm{n}_{\mathrm{Si}, \text { glob }}$ the number of silicon atoms per unit cell. (Si:Al)glob is the global Si:Al ratio, and ( $\mathrm{Si}: \mathrm{Al})_{\mathrm{loc}}$ represents the average local Si:Al ratio around an extraframework cation. If $\alpha \mathrm{NaAl}>1$ it indicates that extraframework cations are located close to the aluminum atom. An $\alpha_{\text {NaAl }}<1$ would indicate that extraframework cations are located close to silicon atoms. And $\alpha_{\mathrm{NaAl}}=1$ indicates that there is no influence of the aluminum atom location on the cation location. This order parameter has been calculated for various materials, having different $\mathrm{Si}: \mathrm{Al}$ ratio and different zeolitic structure, for each cationic site. The data obtained is reported in SI. Except for one case, which will be discussed in further detail later, the order parameter is higher than one. The value of this order parameter highly differs from one cationic site to another. It goes from 1 to 95 . We did not found any general factor to rationalize the value of $\alpha$. 
Table 2. Extraframework cation location in FAU, MOR and LTL zeolites. Simulation results are compared to the available experimental data. The simulated LTL material is hydrated and contains 44 water molecules per unit cell. To our knowledge there is no experimental data concerning cation location in a completely exchange zeolite L.

\begin{tabular}{|c|c|c|c|c|c|c|c|c|}
\hline & $\begin{array}{c}\text { FAU } \\
\text { Sample }\end{array}$ & $\mathbf{I}$ & $\mathbf{I}^{\prime}$ & II & III & III' & $\begin{array}{c}\text { non- } \\
\text { localized }\end{array}$ & ref \\
\hline \multirow{4}{*}{ Simulation } & $\mathrm{Na}_{48} \mathrm{Y}$ & $15 \cdot 5$ & 0.5 & 32.0 & 0 & $\mathrm{O}$ & O & \\
\hline & $\mathrm{Na}_{52} \mathrm{Y}$ & 11.9 & 8.1 & 32.0 & o & $\mathrm{O}$ & o & \\
\hline & $\mathrm{Na}_{64} \mathrm{Y}$ & 0.7 & 31.3 & 32.0 & O & $\mathrm{O}$ & o & \\
\hline & $\mathrm{Na}{ }_{80} \mathrm{Y}$ & 1.0 & 31.0 & 32.0 & 12 & 4 & $\mathrm{O}$ & \\
\hline \multirow[t]{4}{*}{ Experiments } & $\mathrm{Na}_{54} \mathrm{Y}$ & 7.04 & 13.76 & 29.44 & o & $\mathrm{O}$ & 3.76 & 91 \\
\hline & $\mathrm{Na}_{58} \mathrm{Y}$ & $9 \cdot 34$ & 16.67 & 31.04 & o & O & 0.94 & 92 \\
\hline & $\mathrm{Na}_{81} \mathrm{X}$ & 3.84 & 32.0 & 30.78 & 7.87 & o & 6.50 & 92 \\
\hline & $\begin{array}{c}\text { MOR } \\
\text { Sample }\end{array}$ & I & III & IV & VI & & $\begin{array}{c}\text { non- } \\
\text { localized }\end{array}$ & Ref \\
\hline Simulation & $\mathrm{Na}_{8}$ & 3.0 & o & 3.75 & 1.23 & & 0.02 & \\
\hline \multirow[t]{3}{*}{ Experiments } & $\mathrm{Na}_{8}$ & 3.1 & o & 2.6 & 1.5 & & 0.8 & 84 \\
\hline & Na8.1 & 4.0 & 0 & 4.1 & & & & 60 \\
\hline & $\begin{array}{c}\text { LTL } \\
\text { Sample }\end{array}$ & $\mathbf{A}$ & B & C & D & $\begin{array}{l}\text { Total num- } \\
\text { ber of local- } \\
\text { ized cation }\end{array}$ & & Ref \\
\hline Simulation & $\mathrm{Na}_{9}$ & $\mathrm{O}$ & 2.00 & 1.22 & $5 \cdot 59$ & 8.81 & & \\
\hline \multirow[t]{4}{*}{ Experiments } & $\mathrm{Na}_{3} \mathrm{~K}_{6}$ & 1.4 & 2.0 & 2.7 & 3.6 & 9.6 & & 93 \\
\hline & $\mathrm{NaK}$ & O & 2.0 & 2.9 & $5 \cdot 3$ & 10.2 & & 94 \\
\hline & $\mathrm{NaK}$ & 0.0 & 2.0 & 3.0 & 5.1 & 10.1 & & 95 \\
\hline & & $\mathrm{O}$ & 2.0 & 3.0 & 4.0 & 9.0 & & 96 \\
\hline
\end{tabular}

We concentrate our attention to FAU structure, for which all the T-sites are geometrically equivalent, thus having a homogenous aluminum distribution. We studied four different $\mathrm{Si}: \mathrm{Al}$ ratio: $\mathrm{Si}: \mathrm{Al}=3, \mathrm{Si}: \mathrm{Al}=2.69$, $\mathrm{Si}: \mathrm{Al}=2$ and $\mathrm{Si}: \mathrm{Al}=1.4$. As seen before, in these samples, cations occupy sites I, I', II, III, and III', where cationic site were labeled using Smith classification.97 Values of the anaAl calculated for faujasite are reported in Table 3 .

Table 3. Order parameter $\alpha_{\text {NaAl }}$ for the different sites of Faujasite materials (see the text for the definition of $\alpha_{\text {NaAl }}$.

\begin{tabular}{rllll}
\hline $\begin{array}{l}\text { Cationic } \\
\text { site }\end{array}$ & & & & \\
\hline I & 1.03 & 0.85 & & \\
I' & & 1.58 & 1.00 & 1.01 \\
II & 1.00 & 1.00 & 1.00 & 1.00 \\
III & & & & 1.32 \\
III' & & & & 1.16 \\
\hline
\end{tabular}

We can see that for cationic sites that are fully occupied, $\alpha_{\text {NaAl }}$ is equal to one. This is the case of sites II for all Si:Al ratio and sites I for $\mathrm{Na}_{48} \mathrm{Y}$ and of site I' in $\mathrm{Na}_{4} \mathrm{Y}$ and $\mathrm{Na}_{80} \mathrm{X}$. This means that $\mathrm{Si}: \mathrm{Al}_{\text {loc }}$ is equal to $\mathrm{Si}: \mathrm{Al}_{\text {glob }}$. This is linked to the symmetry of Faujasite. We will concentrate on sites II to develop this point. In fact, as said before, all T-sites are equivalent in Faujasite materials, which means that they are all neighbors of site II. Since all site II are occupied, all T sites are neighbors of an occupied site II. When we average the Si:Al ratio on all occupied sites II we thus average on all the different T-sites. Thus, we find that Si:Alloc is equal to Si:Alglob. In $\mathrm{Na}_{52} \mathrm{Y}$ we calculated a value of $\alpha$ NaAl that is higher than one for site I'. This means that the presence of an aluminum atom close to a site I' stabilizes the cation in this site. Surprisingly, in this material the ratio for site I is smaller than one. Since cations are more likely to go closer to aluminum atoms, we did not expect a ratio smaller than one. This unexpected behavior of aluminum atoms close to site I is also due to symmetry reasons. All T-sites are neighbors of a cation in site I or in site I'. If there is an excess of aluminum atoms around site I', this induce a local defect of aluminum atoms in sites I. In $\mathrm{Na}_{80} \mathrm{Y}$ we can see that for sites III and III', $\alpha_{\text {NaAl }}$ is higher than one, which means that the presence of an aluminum atom stabilizes a cation in those sites. 
We can see that many factors may affect the relation between aluminum atoms and extraframework cations. The question is then to know how the aluminum distribution affects the average cationic repartition.

To answer this questions, we have compared the cationic location on two materials belonging to the same zeolitic group, having the same chemical composition but two different structures and thus different aluminum atom distributions. This is the case for Analcimes. We can then compare the cation distribution in different Analcimes samples. We will detail the observed extraframework cation location in ANA1 and ANA6 structures. The results concerning those two structures are reported in Table 4. Experimental data from Mazzi and Galli is also reported. ${ }^{87}$ Structural information as well as additional results for the other Analcime materials can be found in SI.

Table 4. Cation location observed in two different analcimes: ANA1 and ANA6 (structures are labeled according to Mazzi and Galli ${ }^{87}$ ). The cation distribution as well as the aluminum occupancy of the different $\mathrm{T}$ sites of analcime is reported. Experimental data about cation location are shown for comparison. ${ }^{87}$

\begin{tabular}{cccccccc}
\hline & $\begin{array}{c}\text { Aluminum } \\
\text { repartition } \\
\text { (simulation) }\end{array}$ & \multicolumn{4}{c}{ Sodium cation location } \\
\hline Site & $\mathrm{T} 1$ & $\mathrm{~T} 2$ & $\mathrm{Sim}$ & $\mathrm{A}$ & $\mathrm{Exp}$ & $\mathrm{Sim}$ & $\mathrm{Exp}$ \\
$\mathrm{ANA} 1$ & 44.81 & 4.13 & 11.99 & 13.12 & 3.01 & 1.84 \\
ANA6 & 17.77 & 58.20 & 7.22 & 9.76 & 7.77 & 6.16 \\
& & & & & & & \\
\hline
\end{tabular}

In ANA1 cations mainly occupy site A whereas in ANA6 cations mainly occupy sites B. In those two materials, the predicted aluminum atom distribution is different. In ANA1 aluminum are mainly located in site T1 whereas that in ANA6 aluminum atoms mainly occupy site T2. Cationic site A is located closer to site T1, whereas site B is closer to site T2. We can clearly see in this case the influence of the aluminum atoms distribution in the extraframework cation position among the unit cell.

Table 5. Comparison between cation locations calculated with two different models: the T-atoms model and our method with $\mathrm{Si} / \mathrm{Al}$ differentiation (labeled $\mathrm{Si} / \mathrm{Al}$ ) for Faujasite

\begin{tabular}{ccccccc}
\hline & Model & I & I' & II & III & III' \\
\hline \multirow{2}{*}{$\mathrm{Na}_{48} \mathrm{Y}$} & $\mathrm{Si} / \mathrm{Al}$ & 15.5 & 0.5 & 32.0 & 0 & 0 \\
& T-atoms & 15.9 & 0.1 & 32.0 & 0 & 0 \\
\multirow{2}{*}{$\mathrm{Na}_{52} \mathrm{Y}$} & $\mathrm{Si} / \mathrm{Al}$ & 11.9 & 8.1 & 32.0 & 0 & 0 \\
& T-atoms & 12.0 & 8.0 & 32.0 & 0 & 0 \\
$\mathrm{Na}_{64} \mathrm{Y}$ & $\mathrm{Si} / \mathrm{Al}$ & 0.7 & 31.3 & 32.0 & 0 & 0 \\
& T-atoms & 0.5 & 31.5 & 32.0 & 0 & 0
\end{tabular}

\begin{tabular}{lcccccc}
\multirow{2}{*}{$\mathrm{Na} 8 \mathrm{Y}$} & $\mathrm{Si} / \mathrm{Al}$ & 1.0 & 31.0 & 32.0 & 12.0 & 4.0 \\
& $\mathrm{~T}$-atoms & 3.0 & 29.0 & 32.0 & 15.0 & 1.0 \\
\hline
\end{tabular}
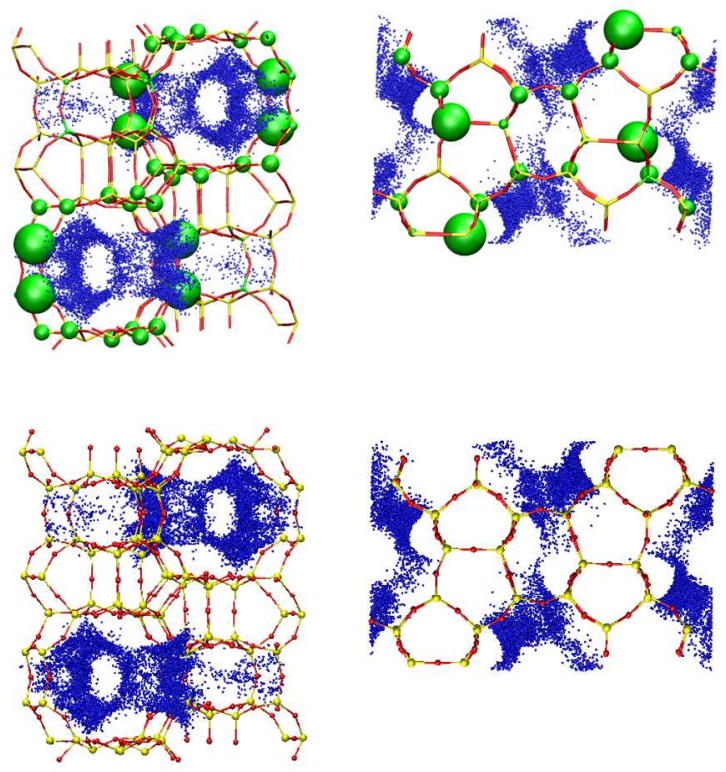

Figure 7. Comparison of $\mathrm{Na}^{+}$cation distribution on MFI zeolite using full Si:Al representation (top) and T-atom approximation (bottom). Two orientations are shown (The MFI model contains 4 aluminums). Small points represent the projection of the center of mass of cations. Size of green spheres (top) represents the percentage of aluminum occupancy on different $\mathrm{T}$ sites.

3.6.3 Comparison between full Si:Al representation vs. T-atom approximation: In order to see the influence of the aluminum atom distribution on the extraframework cation location of zeolites, we can also compare the results of simulation with the new method and the results obtained using the T-atom approach. For different zeolitic materials we calculated the extraframework cation location obtained with both methods. Part of the results is reported in Table 5 . Other results can be found in SI. From those results we classified the zeolites in three different groups.

The first group corresponds to zeolites whose cationic distribution is not sensitive to aluminum atom position. This is the case of LTA and FAU having Si:Al ratio higher than 2.

The second group corresponds to zeolites whose cationic distribution is only slightly modified by the aluminum atom distribution. We thus do not expect a strong influence of the aluminum atoms distribution on the adsorption properties of those materials. This group contains TON, and MFI, MOR and FAU with Si:Al higher than 2. The different distributions of extraframework cations on MFI zeolite between T-atom model and $\mathrm{Si} / \mathrm{Al}$ explicit representation are represented on Figure 7. In MFI, cations are mainly located in intersections but their position in this site slightly differs between the two models. Results obtained for Faujasite 
zeolites are represented in Table 5. In Faujasite zeolites we can observe a displacement from site III to site III'. This effect has already been noticed by Mellot et al.4

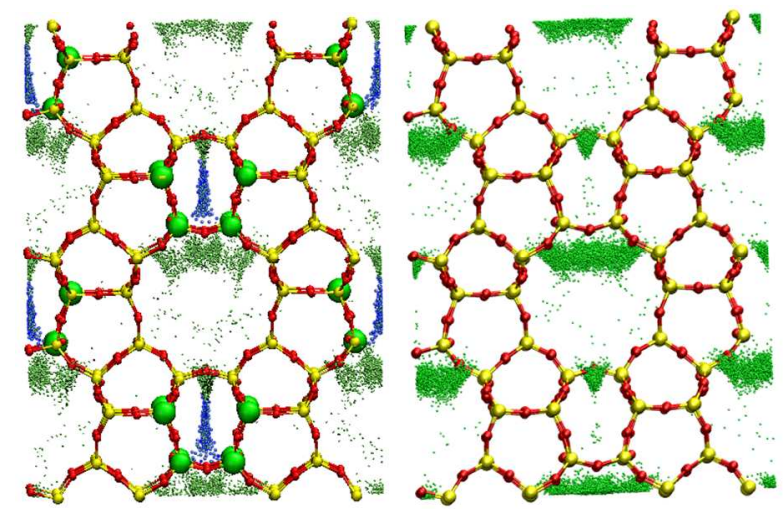

Figure 8. Comparison of $\mathrm{Na}^{+}$cation distribution on MEL zeolite using full $\mathrm{Si}$ :Al representation (left) and T-atom approximation (right). Small green points represent the center of mass projection of cations. Green spheres (left) represent aluminum occupancy on different $\mathrm{T}$ sites. Sphere diameters are proportional to the percentage of occupancy of the sites. Small blue points represent a new site for $\mathrm{Na}^{+}$cations when the full $\mathrm{Si}$ :Al representation is used.

In the third group we find zeolites were the aluminum distribution induces strong rearrangement of the extraframework cations. This group contains MEL, FER and LTL. Figure 8 represent a projection of the cation distribution obtained with the two models for MEL. We can clearly see the formation of a new cationic site when the aluminum atoms are represented explicitly in the simulation.

\section{CONCLUSION AND PERSPECTIVES}

We have presented a new simulation method that allows predicting the aluminum atom distribution in zeolitic framework. The method based on a Monte Carlo algorithm allows predicting both aluminum location and cationic distribution in the material which can be hydrated or not. The only required input of this method is the average experimental structure of the framework, which can be obtained by standard diffraction experiments.

This method has been tested on various zeolites with success. The prediction of aluminum atom repartition is in agreement with the experimental and model data available in the literature. The method using experimental average structure allows to indirectly taking into account the kinetic effects existing in the synthesis pathway. Interactions between aluminum atoms (electrostatics) as well as the local environment (T-O-T angles, T-O distances) are determinant to predict the aluminum distribution.
The cationic location was also predicted with success in various materials. The influence of the aluminum distribution varies from one material to another.

This method can be used for other zeolites, exchanged with different cations and to calculate properties of the material, such as adsorption isotherms.

\section{ASSOCIATED CONTENT}

Supporting Information.

The Supporting Information is available free of charge on the ACS Publications website. DOI: 10.1021/acs.chemmater.XXXX.

Complete description of the solid structures, simulation methods and forcefield parameters. Additional results for Analcime (ANA), Faujasite (FAU), Ferrierite (FER), Goosecreekite (GOO), Linde Type A (LTA), Linde Type L (LTL), Mordenite (MOR), Natrolite (NAT), Theta-1 (TON), Mobil FIve (MFI), and Mobil ELeven (MEL) structures.

\section{AUTHOR INFORMATION}

\section{Corresponding Author}

* E-mail: anne.boutin@ens.fr

\section{Present Addresses}

${ }^{\dagger}$ Marie Jeffroy is now at Saint-Gobain Glass, 39 quai Lucien Lefranc, 93303 Aubervillliers. France

\section{Notes}

The authors declare no competing financial interest.

\section{ACKNOWLEDGMENT}

The authors thank Francesco di Renzo for fruitful discussion on this topic.

\section{REFERENCES}

(1) Baerlocher, C.; Meier, W. M.; Olson, D. H. Atlas of zeolite framework types; Elsevier Science, 2001

(2) Hartmann, M., Machoke, A.G., Schwieger, W. Catalytic test reactions for the evaluation of hierarchical zeolites. Chem. Soc. Rev. 2016, 45, 3313-3330

(3)Fang, H.J.; Kulkarni, A.; Kamakoti, P.; Awati, R.; Ravikovitch, P.I.; Sholl, D.S. Identification of High-CO2-Capacity Cationic Zeolites by Accurate Computational Screening. Chem. of Mat. 2016, 28, 38873896

(4) Mellot-Draznieks, C.; Buttefey, S.; Boutin, A.; Fuchs, A. H. Placement of cations in NaX faujasite-type zeolite using $(\mathrm{N}, \mathrm{V}, \mathrm{T})$ Monte Carlo simulations. Chem. Comm. 2001, 2200-2201.

(5) García-Pérez, E.; Dubbeldam, D.; Liu, B.; Smit, B.; Calero, S. A. A computational method to characterize framework aluminum in aluminosilicates. Ang. Chem. Int. Ed. 2007, 46, 276--278.

(6) Liu, B.; Garcia-Perez, E.; Dubbeldam, D.; Smit, B.; Calero, S. Understanding aluminum location and non-framework ions effects on alkane adsorption in aluminosilicates: A molecular simulation study. J. Phys. Chem. C 2007, 111, 10419-10426.

(7) Lowenstein, W. The distribution of aluminum in the tetrahedra of silicates and aluminates. Am. Mineral 1954, 39, 92-96 
(8) Tarling, S. E.; Barnes, P.; Klinowski, J. The structure and Si,Al distribution of the ultramarines. Acta Cryst. B Struct. Sci. 1988, 44, 128-135

(9) Massiani, P.; Fajula, F.; Figueras, F.; Sanz, J. ${ }^{29} \mathrm{Si}$ and ${ }^{27} \mathrm{Al}$ MAS NMR study of the distribution of $\mathrm{Si}$ and $\mathrm{Al}$ atoms in various forms of synthetic zeolite omega. Zeolites 1988, 8, 332-337

(10) Newsam, J. M. Aluminum partitioning in zeolite-L. J. of the Chem. Soc. - Chem. Comm. 1987, 123-124

(11) Alberti, A.; Gottardi, G.; Lai, T. The determination of (Si. Al) distribution in zeolites. In Guidelines for Mastering the Properties of Molecular Sieves: Relationship Between the Physicochemical Properties of Zeolitic Systems and Their Low Dimensionality; Barhomeuf, D.; Derouane, E.G.; Hölderich, W. Eds.; Springer US: New York, 1990; pp 145-156

(12) Han, O. H.; Kim, C. S.; Hong, S. B. Direct evidence for the nonrandom nature of Al substitution in zeolite ZSM-5: an investigation by ${ }^{27} \mathrm{Al}$ MAS and MQ MAS NMR. Ang. Chem. Int. Ed. 2002, 41 , 469-472

(13) Fyfe, C.; Gobbi, G.; Kennedy, G.; Graham, J.; Ozubko, R.; Murphy, W.; Bothner-By, A.; Dadok, J.; Chesnick, A. Detailed interpretation of the ${ }^{29} \mathrm{Si}$ and ${ }^{27} \mathrm{Al}$ high-field MAS NMR spectra of zeolites offretite and omega. Zeolites 1985, 5, 179-183

(14) Sanz, J.; Herrero, C. P.; Robert, J. L. Distribution of Si and Al in clintonites: A combined NMR and Monte Carlo study. J. Phys. Chem. B 2003, 107, 8337-8342

(15) Kato, M.; Itabashi, K.; Matsumoto, A.; Tsutsumi, K. Characteristics of MOR framework zeolites synthesized in Fluoride-Containing media and related ordered distribution of $\mathrm{Al}$ atoms in the framework. J. Phys. Chem. B 2003, 107, 1788-1797

(16) Sklenak, S.; Dedecek, J.; Li, C.; Wichterlova, B.; Gabova, V.; Sierka, M.; Sauer, J. Aluminum siting in silicon-rich zeolite frameworks: A combined high-resolution ${ }^{27} \mathrm{Al}-\mathrm{NMR}$ spectroscopy and quantum mechanics/molecular mechanics study of ZSM-5. Angew. Chem. Int. Ed. 2007, 46, 7286-7289

(17) Dedecek, J.; Sklenak, S.; Li, C.; Gao, F.; Brus, J.; Zhu, Q.; Tatsumi, T. Effect of Al-Si-Al and Al-Si-Si-Al pairs in the ZSM-5 zeolite framework on the ${ }^{27} \mathrm{Al}$ NMR spectra. A combined highresolution ${ }^{27} \mathrm{Al}$ NMR and DFT/MM study. J. Phys. Chem. C 2009, $113,14454-14466$

(18) Sklenak, S.; Dedecek, J.; Li, C.; Wichterlova, B.; Gabova, V.; Sierka, M.; Sauer, J. Aluminum siting in the ZSM-5 framework by combination of high resolution ${ }^{27} \mathrm{Al}$ NMR and DFT/MM calculations Phys. Chem. Chem. Phys. 2009, 11, 1237

(19) Dedecek, J.; Sklenak, S.; Li, C.; Wichterlova, B.; Gabova, V.; Brus, J.; Sierka, M.; Sauer, J. Effect of Al-Si-Al and Al-Si-Si-Al Pairs in the ZSM-5 Zeolite Framework on the ${ }^{27} \mathrm{Al}$ NMR Spectra. A Combined High-Resolution ${ }^{27} \mathrm{Al}$ NMR and DFT/MM Study. J. Phys. Chem. C 2009, 113, 1447-1458

(20) Bokhoven, J. A. V.; Koningsberger, D. C.; Kunkeler, P.; Bekkum, H. V. Effect of aluminum on the local structure of silicon in zeolites as studied by Si K edge Xray absorption Near-Edge fine structure: Spectra simulation with a Non-Muffin tin atomic background. $J$. of Cat. 2002, 211, 540-547

(21) Bugaev, L.; van Bokhoven, J.; Khrapko, V.; Avakyan, L.; Latokha, J. Effect of aluminum on the local structure of silicon in zeolites as studied by $\mathrm{Si} \mathrm{K}$ edge Xray absorption Near-Edge fine structure: Spectra simulation with a Non-Muffin tin atomic background. J. Phys. Chem. B 2009, 113, 4614-4618

(22) van Bokhoven, J. A.; van der Eerden, A. M. J.; Koningsberger, D. C. Three-coordinate aluminum in zeolites observed with in situ Xray absorption Near-Edge spectroscopy at the al K-Edge: flexibility of aluminum coordinations in zeolites. J. Am. Chem. Soc. 2003, 125, 7435-7442

(23) Van Bokhoven, J. A.; Lee, T. L.; Drakopoulos, M.; Lamberti, C.; Thiss, S.; Zegenhagen, J. Determining the aluminium occupancy on the active T-sites in zeolites using X-ray standing waves. Nat. Mater. 2008, 7, 551-555

(24)Vjunov, A.; Fulton, JL; Huthwelker, T.; Pin, S.; Mei, D.H.; Schenter, G.K.; Govind, N.; Camaioni, D.M.; Hu, J.Z.; Lercher, J.A.
Quantitatively Probing the $\mathrm{Al}$ Distribution in Zeolites. J. Am. Chem. Soc. 2014, 136, 8296-8306

(25) Jones, J. B. Al-O and Si-O tetrahedral distances in aluminosilicate framework structures. Acta Crystallographica Section B: Structural Crystallography and Crystal Chemistry 1968, 24, 355-358

(26) Ribbe, P. H.; Gibbs, G. V. Statistical analysis and discussion of mean $\mathrm{Al} / \mathrm{Si}-\mathrm{O}$ bond distances and the aluminum content of tetrahedra in feldspars. Am. Miner. 1969, 54, 85-94

(27) Alberti, A.; Gottardi, G. The determination of the Al-content in the tetrahedra of framework silicates. Zeitschrift für Kristallographie 1988, $184,49-61$

(28) Sanders, M. J.; Catlow, R. A.; Smith, J. V. Crystal energy calculations from strontium ions in zeolite A. J. Phys. Chem. 1984, 88, 2796-2797

(29) Oumi, Y.; Kanai, T.; Lu, B.; Sano, T. Structural and physicochemical properties of high-silica mordenite. Micr. Mes. Mat. 2007, $101,127-133$

(30) Grau-Crespo, R.; Peralta, A. G.; Ruiz-Salvador, A. R.; Gomez, A.; Lopez-Cordero, R. A computer simulation study of distribution, structure and acid strength of active sites in H-ZSM-5 catalyst. Phys. Chem. Chem. Phys. 2000, 2, 5716-5722

(31) Ruiz-Salvador, A.; Lewis, D.; Rubayo-Soneira, J.; RodriguezFuentes, G.; Sierra, L.; Catlow, C. Aluminum distribution in low Si/Al zeolites : Dehydrated Naclinoptilolite. J. Phys. Chem. B 1998, 102, $8417-8425$

(32) Channon, Y. M.; Catlow, C. R. A.; Jackson, R. A.; Owens, S. L. A computational investigation into the effect of extra framework cations on the structural composition of heulandite-type zeolites. Mic. Mes. Mat. 1998, 24, 153-161

(33) Ruiz-Salvador, A. R.; Gomez, A.; Lewis, D. W.; RodriguezFuentes, G.; Montero, L. Silicon-aluminium distribution in dehydrated calcium heulandite. Phys. Chem. Chem. Phys. 1999, 1, 1679-1685

(34) Ruiz-Salvador, A. R.; Gomez, A.; Lewis, D. W.; Catlow, C. R. A.; Rodriguez-Albelo, L. M.; Montero, L.; Rodriguez-Fuentes, G. Clinoptilolite-heulandite polymorphism : structural features from computer simulation. Phys. Chem. Chem. Phys. 200o, 2, 1803-1813

(35) Ruiz-Salvador, A. R.; Almora-Barrios, N.; Gomez, A.; Lewis, D. W. Interplay of water, extra-framework cations and framework atoms in the structure of low-silica zeolites : the case of the natural zeolite goosecreekite as studied by computer simulation. Phys. Chem. Chem. Phys. 2007, 9, 521-532

(36) French, S.A.; Coates, R.; Lewis, D.W.; Catlow, C.R. Probing the structure of complex solids using a distributed computing approach-Applications in zeolite science. J. Solid State Chem. 2011, 184, 1484-1491

(37) Soukoulis, C. M. Monte Carlo simulations of zeolites. J. Phys. Chem. 1984, 88, 4898-4901

(38) Herrero, C. P. Short-range order of the silicon/aluminum distribution on the faujasite framework. J. Phys. Chem. 1991, 95, 32823288

(39) Herrero, C. P.; Utrera, L.; Ramírez, R. Long- versus shortrange $\mathrm{Si}, \mathrm{Al}$ ordering in zeolites $\mathrm{X}$ and $\mathrm{Y}$. Chem. Phys. Lett. 1991, 183, 199-203

(40) Gordillo, M. C.; Herrero, C. P. Al, Si ordering in chabazites: A Monte Carlo study. Chem. Phys. 1996, 211, 81-90

(41) Li, B.; Sun, P.; Jin, Q.; Wang, J.; Ding, D. A simulated annealing study of $\mathrm{Si}, \mathrm{Al}$ distribution in the omega framework. J. of Mol. Cat A: Chemical 1999, 148, 189-195

(42) Hong, S. B.; Lee, S. H.; Shin, C. H.; Woo, A. J.; Alvarez, L. J.; Zicovich-Wilson, C. M.; Camblor, M. A. In situ disorder-order transformation in synthetic gallosilicate zeolites with the NAT topology. $J$. Am. Chem. Soc. 2004, 126, 13742-13751

(43) Kosinov, N., Gascon, J., Kapteijn, F., Hensen, E.J.M. Recent developments in zeolite membranes for gas separation. J. Memb. Sci. 2016, 499, 65-79

(44) Krishna, R.Separating mixtures by exploiting molecular packing effects in microporous materials. Phys. Chem. Chem. Phys. 2015 $17,39-59$ 
(45) Liu, D.-J., Garcia, A., Wang, J., Ackerman, D.M., Wang, C.-J., Evans, J.W. Kinetic Monte Carlo Simulation of Statistical Mechanical Models and Coarse-Grained Mesoscale Descriptions of Catalytic Reaction-Diffusion Processes: 1D Nanoporous and 2D Surface Systems. Chem. Rev. 2015, 115, 5979-6050

(46) Krishna, R. The Maxwell-Stefan description of mixture diffusion in nanoporous crystalline materials. Mic. and Mes. Mat. 2014, $185,30-50$

(47) Combariza, A.F., Gomez, D.A., Sastre, G. Simulating the properties of small pore silica zeolites using interatomic potentials (2013) Chem. Soc. Rev. 2013, 42, 114-127

(48) Auerbach, S. M.; Bull, L. M.; Henson, N. J.; Metiu, H. I.; Cheetham, A. K. Behavior of benzene in $\mathrm{Na}-\mathrm{X}$ and $\mathrm{Na}-\mathrm{Y}$ zeolites Comparative study by H2 NMR and molecular mechanics. J. Phys. Chem. 1996, 100, 5923-5930

(49) Jaramillo, E.; Auerbach, S. M. New force field for Na cations in faujasite-type zeolites. J. Phys. Chem. B 1999, 103, 9589-9594

(50) Di Lella, A.; Desbiens, N.; Boutin, A.; Demachy, I.; Ungerer, P.; Bellat, J. P.; Fuchs, A. H. Molecular simulation studies of water physisorption in zeolites. Phys. Chem. Chem. Phys. 2006, 8, 53965406

(51) Calero, S.; Dubbeldam, D.; Krishna, R.; Smit, B.; Vlugt, T. J.; Denayer, J. F.; Martens, J. A.; Maesen, T. L. Understanding the role of sodium during adsorption: A force field for alkanes in sodiumexchanged faujasites. J. Am. Chem. Soc. 2004, 126, 11377-11386

(52) Demontis, P.; Suffritti, G. B.; Quartieri, S.; Fois, E. S.; Gamba, A. Molecular dynamics studies on zeolites. 3. Dehydrated zeolite A. $J$. Phys. Chem. 1988, 92, 867-871

(53) Kramer, G. J.; Farragher, N. P.; van Beest, B. W. H.; van Santen, R. A. Interatomic force fields for silicas, aluminophosphates, and zeolites: Derivation based on ab initio calculations. Phys. Rev. B 1991, $43,5068-5080$

(54) Smirnov, K. S.; Bougeard, D. A molecular dynamics computer study of window fluctuations in zeolite A. Zeolites 1994, 14, 203-207

(55) Demontis, P.; Suffritti, G. B. Structure and dynamics of zeolites investigated by molecular dynamics. Chem. Rev. 1997, 97, 28452878

(56) Ramsahye, N. A.; Bell, R. G. Cation mobility and the sorption of chloroform in zeolite NaY: molecular dynamics study. $J$. Phys. Chem. B 2005, 109, 4738-4747

(57) Leroy, F.; Rousseau, B.; Fuchs, A. H. Self-diffusion of nalkanes in silicalite using molecular dynamics simulation: A comparison between rigid and flexible frameworks. Phys. Chem. Chem. Phys.2004, 6, 775-783

(58) Nicholas, J. B.; Hopfinger, A. J.; Trouw, F. R.; Iton, L. E. Molecular modeling of zeolite structure. 2. Structure and dynamics of silica sodalite and silicate force field. J. Am. Chem. Soc. 1991, 113, $4792-4800$

(59) Jeffroy, M.; Nieto-Draghi, C.; Boutin, A. Molecular simulation of zeolite flexibility. Mol. Sim. 2014, 4O, 6-15

(60) Maurin, G.; Senet, P.; Devautour, S.; Gaveau, P.; Henn, F.; Van Doren, V. E.; Giuntini, J. C. Combining the Monte Carlo technique with ${ }^{29} \mathrm{Si}$ NMR spectroscopy: Simulations of cation locations in zeolites with various $\mathrm{Si} / \mathrm{Al}$ ratios. J. Phys. Chem. B 2001, 105, 91579161

(61) Buttefey, S.; Boutin, A.; Mellot-Draznieks, C.; Fuchs, A. A simple model for predicting the $\mathrm{Na}+$ distribution in anhydrous $\mathrm{NaY}$ and NaX zeolites. J. Phys. Chem. B 2001, 105, 9569-9575

(62) R. J. Haüy. Traité de minéralogie . Chez Louis (1801).

(63) Mortier W. J. and International Zeolite Association. Structure Commission. Compilation of extra frameword sites in zeolites. Butterworth \& Co.(Publishers) Ltd (1982).

(64) Vaughan. P. A. Crystal structure of zeolite ferrierite. Acta Crystallographica 1966, 21, 983-990.

(65) Rouse, R. C.; Peacor, D. R. Crystal structure of the zeolite mineral goosecreekite, $\mathrm{CaAl}_{2} \mathrm{Si}_{6} \mathrm{O}_{16} .5 \mathrm{H}_{2} \mathrm{O}$. American Mineralogist 1986 , $71,1494-1501$

(66) Fyfe, C. A.; Kennedy, G. J.; Kokotailo, G. T.; Deschutter, C. T. Investigation of the dealumination of high silica zeolite A (ZK-4) by
${ }^{29}$ Si magic angle-spinning NMR spectroscopy. Journal of the Chemical Society - Chemical Communication 1984, 16, 1093-1094.

(67) Artioli, G. Kvick, A. Synchrotron X-Ray rietveld study of perlialite, the natural counterpart of synthetic zeolite-L. European Journal of Mineralogy 1990, 2, 749-759.

(68) Klinowski, J. Ramdas, S.; Thomas, J. M.; Fyfe, C. A.; Hartman J. S. A re-examination of $\mathrm{Si}, \mathrm{Al}$ ordering in zeolites $\mathrm{NaX}$ and $\mathrm{NaY}$. Journal of the Chemical Society, Faraday Transactions 1982, 78, 1025-1050.

(69) Sulikowski, B. Klinowski, J. Dealumination of zeolites with silicon tetrachloride vapour. Part 6. Zeolites Li,Na-X and Li,Na-Y. Journal of the Chemical Society, Faraday Transactions 1990, 86, 199204

(70) Barri, S. A. I.; Smith, G. W., White, D.; Young, D. Structure of theta-1, the first unidimensional medium-pore high-silica zeolite. Nature 1984, 312, 533-534.

(71) Olson, D. H.; Kokotailo, G. T.; Lawton, S. L.; Meier, W. M. Crystal-structure and structure-related properties of ZSM-5. Journal of Physical Chemistry 1981, 85, 2238-2243.

(72) Kokotailo, G. T.; Chu, P.; Lawton, S. L.; Meier, W. M. Synthesis and structure of synthetic zeolite ZSM-11. Nature 1978, 275, 119120.

(73) Fuchs, A. H.; Cheetham, A. K. Adsorption of guest molecules in zeolitic materials: Computational aspects. J. Phys. Chem. B 2001, 105, $7375-7383$

(74) Pascual, P.; Ungerer, P.; Tavitian, B.; Pernot, P.; Boutin, A. Phys. Chem. Chem. Phys. 2oo3, 5, 3684

(75) Pascual, P.; Boutin, A. Adsorption of hydrocarbons in zeolites from molecular simulations. The alkane-ferrierite system revisited. Phys. Chem. Chem. Phys. 2004, 6, 2015

(76) Desbiens, N.; Demachy, I.; Fuchs, A. H.; Kirsch-Rodeschini, H.; Soulard, M.; Patarin, J. Water condensation in hydrophobic nanopores. Angew. Chem. Int. Edit. 2005, 44, 5310--5313

(77) Trzpit, M.; Soulard, M.; Patarin, J.; Desbiens, N.; Cailliez, F.; Boutin, A.; Demachy, I.; Fuchs, A.H. The Effect of local silanol defects on water adsorption in Silicalite-1 zeolite. A joint experimental and molecular simulation study. Langmuir 2007, 23, 10131-10139

(78) Coudert, F.; Cailliez, F.; Vuilleumier, R.; Fuchs, A. H.; Boutin, A. Water nanodroplets confined in zeolite pores. Faraday Discuss. 2009, 141, 377

(79) Cailliez, F.; Trzpit, M.; Soulard, M.; Demachy, I.; Boutin, A.; Patarin, J.; Fuchs, A. H. Thermodynamics of water intrusion in nanoporous hydrophobic solids. Phys. Chem. Chem. Phys. 2008, 10, 4817-4826

(80) Jorgensen, W. L.; Chandrasekhar, J.; Madura, J. D.; Impey, R. W.; Klein, M. L. Comparison of simple potential functions for simulating liquid water. J. Chem. Phys. 1983, 79, 926-935

(81) Dang, L. Mechanism and thermodynamics of ion selectivity in aqueous-solutions of 18 -crown-6 ether. A molecular-dynamics study. J. Am. Chem. Soc. 1995, 117, 6954-6960

(82) Fälth, L.; Hansen, S. Structure of scolecite from Poona, India Acta Cryst. Section B 1979, 35, 1877-1880

(83) Alberti, A.; Gottardi, G. On the influence of ( $\mathrm{Si}$-Al) disorder on the TO distances measured in zeolites. Zeolites Synthesis Structure, Technology and Application 1985, 255-261

(84) Schlenker, J. L.; Pluth, J. J.; Smith, J. V. Positions of cations and molecules in zeolites with the mordenite-type framework. VIII. Dehydrated sodium-exchanged mordenite. Mat. Res. Bull 1979, 14, $751-758$

(85) Shiokawa, K.; Ito, M.; Itabashi, K. Crystal-structure of synthetic mordenites. Zeolites 1989, 9, 170-176

(86) Meier, W. M.; Meier, R.; Gramlich, V. Mordenite : Interpretation of a superposed structure. Zeitschrift für Kristallographie 1978, 147,329

(87) Mazzi, F.; Galli, E. Is each analcime different? Am. Mineral. $\mathbf{1 9 7 8}, 63,448-460$

(88) Ruiz-Salvador, A.R.; Grau-Crespo, R.; Gray, A.E.; Lewis, D.W. Aluminium distribution in $\mathrm{ZSM}-5$ revisited: The role of $\mathrm{Al}-\mathrm{Al}$ interactions J. of. Solid State Chem. 2013, 198, 330-336 
(89) Bellat, J.; Paulin, C.; Jeffroy, M.; Boutin, A.; Paillaud, J.; Patarin, J.; Di Lella, A.; Fuchs, A.H. Unusual hysteresis loop in the Adsorption-Desorption of water in NaY zeolite at very low pressure. $J$. Phys. Chem. C 2009, 113, 8287-8295

(90) Baerlocher, C.; Barrer, R. M. The structure of the synthetic zeolite (K, Ba)-G, L. Zeitschrift fur Kristallographie 1972, 136, 245-254

(91) Mortier, W. J.; Van Den Bossche, E.; Uytterhoeven, J. B. Influence of the temperature and water adsorption on the cation location in Na-Y zeolites. Zeolites 1984, 4, 41-44

(92) Hseu, T. Ph. D. Thesis. University of Washington, 1972

(93) Barrer, R. M.; Villiger, H. The crystal structure of the synthetic zeolite L. Zeitschrift für Kristallographie 1969, 128, 352-370

(94) Wright, P. A.; Thomas, J. M.; Cheetham, A. K.; Nowak, A. K. Localizing activesites in zeolitic catalysts - Neutron powder profile analysis and computer-simulation of deuteropyridine bound to Gallozeolite-L. Nature 1985, 318, 611-614

(95) Newsam, J. M. Structural characterization of dehydrated gallium zeolite-L. Mat. Res. Bull. 1986, 21, 661-672

(96) Takaishi, T. Ordered distribution of aluminum or gallium atoms in zeolite-L. J. of the Chem. Soc., Faraday Transact. 1988, 84, 2967-2977

(97) Smith, J. Chapter 15 : Faujasite-type structures : Aluminosilicate framework: Positions of cations and molecules : Nomenclature. In Molecular Sieves I; ACS Advances in Chemistry Series; Oxford University Press: Washington D.C., 1971, 101, 171-200 


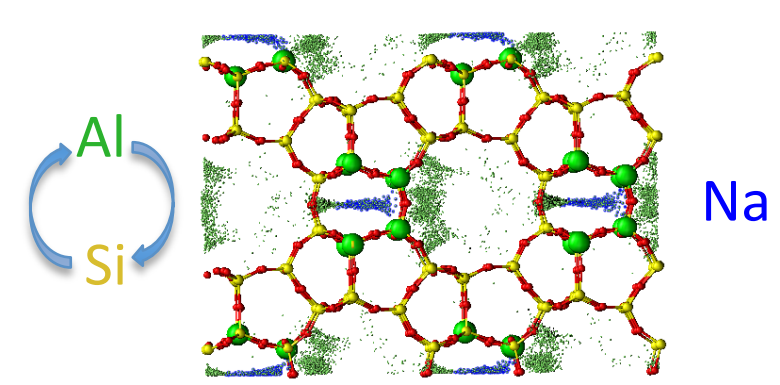

ACS Paragon Plus Environment 